\title{
ECONOMIC GROWTH, TECHNOLOGICAL PROGRESS AND SOCIAL CAPITAL: THE INVERTED U HYPOTHESIS
}

\author{
Angelo Antoci, Fabio Sabatini and Mauro Sodini* \\ Università di Sassari, Sapienza Università di Roma and Università di Pisa \\ (October 2011; revised October 2012)
}

\begin{abstract}
We set up a theoretical framework to analyse the role of economic growth and technological progress in the erosion of social capital. Under certain conditions on parameters, the relationship between technological progress and social capital can take the shape of an inverted U curve. Furthermore, we show the circumstances that allow the economy to follow trajectories where the stock of social capital grows endogenously and unboundedly.
\end{abstract}

\section{INTRODUCTION}

Robert Putnam (2000) has documented how most indicators of social capital followed an inverted U path in the USA during the 20th century: during the first two-thirds of the century 'Americans took a more and more active role in the social and political life of their communities', and they behaved in an increasingly trustworthy way towards one another (2000, p. 183). Then, beginning in the 1960s and 1970s and accelerating in the 1980s and 1990s, an erosion of the stock of American social capital started. Apparently, year by year Americans became less generous and trustworthy, less engaged in community problems and less inclined to meet their friends, neighbours and acquaintances.

\footnotetext{
* The paper benefited from comments by participants at conferences in Ancona, Bento Gonçalves, Paris and Santander and at seminars held in Forlì, Rome and Trento. Mauro Sodini acknowledges that this work has been performed within the activity of the PRIN project 'Local interactions and global dynamics in economics and finance: models and tools', MIUR, Italy. We are grateful to two anonymous referees whose comments allowed a substantial improvement of the paper. Materials for the study of social capital, economic growth and technology are retrievable at the Social Capital Gateway, a website edited by the corresponding author of this article at the address http://www.socialcapitalgateway.org. Needless to say, the usual caveats apply.
} 
The author discusses three main explanations for this inverted $\mathrm{U}$ trend: pressure on time and money, mobility and sprawl, and technology and mass media. Pressures on time and money, as well as mobility and sprawl, have been considered in the economic and sociological literature as channels through which economic growth can bring about a side-effect of reduced social connectedness (Wellman, 2001; Routledge and von Amsberg, 2003; van Ingen and Dekker, 2011). However, as Putnam (2000) states, it is difficult to find evidence of an association between economic growth, pressure on time and money, and the decline in civic and social engagement experienced in the USA. The author instead points to technological progress as a possible reason for the erosion of the American social capital. Technology has in fact made news and entertainment increasingly individualized. In Putnam's words, people do not have to coordinate their 'tastes and timing with others in order to enjoy the rarest culture or the most esoteric information ... Electronic technology allows us to consume hand-tailored entertainment in private, even utterly alone' (pp. 216-17). Putnam notes that it was throughout the 1970s - just as civic and social disengagement was gathering steam in the USA - that the time allocation of Americans 'massively shifted towards home-based activities (especially watching TV) and away from socializing outside the home' (p. 238).

In this paper, we develop a dynamic model integrating Putnam's hypothesis and other promising hints from the sociological and the economic literature, with the objective to better understand how economic growth and technological progress may influence the accumulation of social capital.

We assume that the well-being of individuals depends on two kinds of goods: material and relational. Relational goods are a distinctive type of good that can only be enjoyed if shared with others. They are different from private goods, which are enjoyed alone (Uhlaner, 1989). Following Coleman (1988, 1990), we assume that social participation (i.e. the production/ consumption of relational goods) generates social capital as a by-product. Social capital is here defined as the sum of durable ties that agents develop through their social participation. Furthermore, following insights from political science (see, for example, Hochschild, 1997), we assume that on-thejob interactions can also stimulate the creation of interpersonal ties.

As sustained by Coleman (1988), the stock of social capital functions as a public good, which enters as an argument in the agents' utility functions and as an input in the production of both private and relational goods. In this way, we intend to model one of the most debated claims emerging from the empirical literature: the positive role of social capital in material production and economic growth (Knack and Keefer, 1997; Paldam and Svendsen, 2000; Beugelsdijk and van Schaik, 2005; Bjørnskov, 2012). 
Finally, we assume that private and relational goods can substitute for each other in the satisfaction of individual relational needs. For example, when the social environment is poor, people may be constrained to replace human interactions, such as playing football with friends, with private consumption, such as staying at home and watching a TV show. However, relational goods cannot satisfy primary needs such as food, security, clothing and shelter.

The analysis of dynamics shows that the economy may be attracted by alternative steady states, depending on the initial wealth of social capital and on exogenous parameters representing the importance of relational goods in well-being and production. The possibility exists for the economy to fall in a 'social poverty trap' (in the sense of Antoci et al., 2001, 2007), where agents devote all their time to private activities.

The introduction of exogenous technical progress in the production function of private goods causes interesting changes in social capital's accumulation dynamics.

In case of positive Edgeworth substitutability between private and relational goods (see section 2 for details), social capital may experience growth followed by a decline, so that its relationship with technological progress can be described by an inverted U-shaped curve similar to the trends reported in Putnam's Bowling Alone. Along this curve, private activities infinitely expand at the expense of social interaction, thereby trapping the economy in a situation of social poverty. However, also in the context of substitutability, if the initial endowments of social capital are high enough, the economy can follow a growth path along which both technological progress and social capital grow indefinitely.

The outline of the paper is as follows. Sections 2 and 3 present the model and analyse its dynamics. Section 4 studies the effect of exogenous technical progress on the dynamics of social capital. The paper ends with a brief discussion of the main results.

\section{THE MODEL}

We consider a population of size 1 constituted by a continuum of identical individuals. We assume that, in each instant of time $t$, the well-being of the individual $i \in[0,1]$ depends on the consumption of two goods: a private material good, $C_{i}(t)$, and a socially provided good, $B_{i}(t)$. We assume that $B_{i}(t)$ is produced through the joint action of the time devoted by agent $i$ to social activities, $s_{i}(t)$, the aggregate social participation $\bar{s}(t)=\int_{0}^{1} s_{i}(t) d i$, and the stock of social capital $K_{s}(t)$ : 


$$
B_{i}(t)=F\left[s_{i}(t), \bar{s}(t), K_{s}(t)\right]
$$

Since relational goods can be enjoyed only if shared with others, their production process depends on the social participation of others and on the stock of networks existing in the surrounding environment. A peculiarity of relational goods is that it is virtually impossible to separate their production from consumption, since they coincide (Gui and Sugden, 2005). For example, a football match with friends is enjoyed (consumed) in the very moment of its production (i.e. the 90 minutes spent on the sports field).

This way of modelling relational goods differs from the approach followed by Bilancini and D'Alessandro (2012), where relational goods are assumed to be function of the leisure time enjoyed by individuals and of the current stock of social ties. This stock in turn depends on the average level of leisure enjoyed in the economy and on the depreciation rate of social ties over time. In their work, the average level of social participation thus exerts a 'lagged' effect on the individual's consumption of relational goods, via the accumulation of social capital. Starting from the assumption that relational goods can be enjoyed if they are shared with others, in this paper we aim to acknowledge the role of the externalities caused by the others' current relational behaviour by modelling $B_{i}(t)$ also as a function of the current aggregate level of relational goods' consumption, $\bar{s}(t)$. From this point of view, a distinctive feature of Bilancini and D'Alessandro's (2012) way to model relational goods is that, by entailing a 'lagged' effect of the current level of the aggregate relational goods' consumption, the authors' framework implicitly account for (and model) the possibility of asynchronous interactions between individuals, which are typical of the 'social networking era' (i.e. the pervasive use of networks such as Facebook and Twitter). As suggested in Antoci et al. (2012a), online networking in fact yields a 'storage mechanism' through which any individual contribution - e.g. a blog post, a comment or a photo - is stored within a particular network and ready for virtual access by each member who connects to the network. When someone provides feedback, e.g. by commenting on a note, or by replying to a message, the interaction is 'finalized'. These asynchronous interactions allow individuals to relate in different moments, whenever they have time to, thereby offering a way to counterbalance the possibly negative effects of growth - such as, for example, those related to the need to increase the number of hours worked-on social participation (on this point, which will be reprised below within the description of the model's specification, see Bartolini and Bonatti, 2008; Bartolini and Bilancini, 2011). 
In our model, agents have to choose how to allocate their time between the two types of production (of private vs. relational goods). The time agent $i$ does not spend for social participation, $1-s_{i}(t)$, is used as input in the production and consumption of the output $Y_{i}(t)$ of the private good. As suggested by Antoci et al. (2012b), we assume that social capital also plays a role in the production process of the private good. In this way, we model the claim raised by previous empirical studies that sociocultural traits-often grouped together under the common label of social capital - are factors that enhance the production of material goods (Knack and Keefer, 1997; Paldam and Svendsen, 2000; Sequeira and Ferreira-Lopes, 2011). In addition, for simplicity, we assume that $C_{i}(t)=Y_{i}(t)$, i.e. $Y_{i}(t)$ cannot be accumulated, and that the production process of $Y_{i}(t)$ requires only the inputs $1-s_{i}(t)$ and $K_{s}(t)$ :

$$
C_{i}(t)=Y_{i}(t)=G\left[1-s_{i}(t), K_{s}(t)\right]
$$

The functions $F$ and $G$ in (1) and (2) are assumed to be strictly increasing in each argument. Note that, in this context, $1-s_{i}(t)$ can be interpreted as the time spent both to produce and to consume $C_{i}(t)$.

Finally, since human relations need care to be preserved, we introduce a positive depreciation rate of social capital to account for their possible cooling over time. The time evolution of social capital is thus expressed by:

$$
\dot{K}_{S}(t)=H[\bar{B}(t), \bar{Y}(t)]-\eta K_{S}(t)
$$

where $\dot{K}_{s}(t)$ indicates the time derivative of $K_{s}(t)$, the parameter $\eta>0$ is the depreciation rate of $K_{s}(t), \bar{B}(t)=\int_{0}^{1} B_{i}(t) d i$ and $\bar{Y}(t)=\bar{C}(t)=\int_{0}^{1} Y_{i}(t) d i$ are the aggregate production/consumption of the socially provided good and the aggregate production of the private good, respectively. The stock $K_{s}(t)$ is a public resource, which enters as an argument in every agent's utility function due to its ability to contribute to the production of both private and relational goods.

For simplicity, we consider the following Cobb-Douglas specifications for $F, G$ and $H$ :

$$
\begin{aligned}
& F\left[s_{i}(t), \bar{s}(t), K_{s}(t)\right]=s_{i}^{\varepsilon}(t) \cdot \bar{s}^{1-\varepsilon}(t) \cdot K_{s}^{\gamma}(t) \\
& G\left[1-s_{i}(t), K_{s}(t)\right]=\left[1-s_{i}(t)\right] \cdot K_{s}^{\alpha}(t) \\
& H[\bar{B}(t), \bar{Y}(t)]=[\bar{Y}(t)]^{\beta} \cdot[\bar{B}(t)]^{\delta}
\end{aligned}
$$

where $\varepsilon \in(0,1)$ measures the productivity of time spent on social interaction in the individuals' production process of relational goods; $\alpha \in(0,1)$ and 
$\gamma \in(0,1)$ measure the productivity of the social capital stock in the production process of the private and relational goods, respectively. Finally, $\beta \in(0$, 1) and $\delta \in(0,1)$ measure the role of the private production and relational goods in the accumulation of social capital, respectively.

Note that a positive average social participation $\bar{s}(t)>0$ is essential for the production/consumption of $B_{i}(t)$, i.e. $B_{i}(t)=0$ if $\bar{s}(t)=0$ whatever the values of $s_{i}(t)$ and $K_{s}(t)$ are. If no one participates, single agents have no opportunity to enjoy relational goods, even in the presence of a positive stock of social capital. If $\gamma>\alpha$, then the role of social capital is more relevant in the production/consumption of relational goods than in the production/ consumption of private goods. Vice versa if $\gamma<\alpha$.

According to (4), $\bar{B}(t)$ and $\bar{Y}(t)$ are both essential factors for the accumulation of social capital, i.e. the stock of social capital $K_{s}(t)$ decreases (i.e. $\left.\dot{K}_{s}(t)<0\right)$ if $\bar{B}(t)=0$ or $\left.\bar{Y}(t)=0\right)$. The function $H$ allows us to account for two assumptions about the contribution of material goods $\bar{Y}(t)$ to the accumulation of social capital $\dot{K}_{s}(t)$. First, the process of private goods production may exert a positive spillover on social capital's accumulation because on-the-job interactions can stimulate the creation of durable ties among workers. Friendships often start on the workplace, both spontaneously and as a result of human resources management strategies. In political science, several studies claim that citizens can develop their relational and political attitudes at the workplace. ${ }^{1}$ Putnam (2000) stresses how workers 'are putting in long hours together, eating lunch together, travelling together, arriving early and staying late ... Work is where the heart is for many solitary souls' (p. 86). Even for the minority who live with spouse and children, argues Hochschild (1997), the workplace increasingly serves as 'a sanctuary from the stresses of marriage, children, and housework'. Work structures are a generator of face-to-face interactions that stimulate the sharing of social norms and the creation of interpersonal ties (Goul Andersen and Hoff, 2001; Schur, 2003). The workplace can thus be considered as a training ground where people may improve those communication and organizational abilities which are crucial for the production and consumption of relational goods.

Second, the consumption of certain types of material goods provides a fundamental contribution to the long-run accumulation of social capital. More specifically, computers and communication devices allowing users to join develop their social participation through online networking now play a

\footnotetext{
${ }^{1}$ Those who possess well-developed relational skills are likely to find social and political participation less daunting and costly (Burn and Konrad, 1987; Brady et al., 1995; Verba et al., 1995). Some authors claim that on the job interactions foster the development of democratic attitudes (Verba et al., 1995), and active political participation (Mutz and Mondak, 2006).
} 
major role in the preservation and development of interpersonal relations (Pasek et al., 2009; Valenzuela et al., 2009; Pénard and Poussing, 2010; Bauernschuster et al., 2011).

As stressed in the reviews of the literature presented in Antoci et al. (2012a, 2012c), participation through online networks can help individuals to maintain their social contacts from distant locations, e.g. after a transfer due to work commitments (Ellison et al., 2007, 2011). Moreover, Web-mediated interaction is less sensitive to a reduction in leisure time caused by an intense pace of work. Facebook and Twitter allow users to stay in touch with their friends and acquaintances during coffee breaks or while waiting for the train. Online social participation favours asynchronous interactions which allow individuals to compensate for the lack of time: one can benefit from the others' participation, e.g. by reading a message or a note, even if the person who wrote is currently offline. As a result, online networking contributes to the building of what has been called Internet social capital, i.e. the accumulation of a stock of knowledge, information and trust within virtual networks (Vergeer and Pelzer, 2009; Chaim and Gandal, 2011; Antoci et al., 2012a, 2012c).

The interactions allowed by Internet use may also negatively affect the depreciation rate $\eta$ of social capital. The growing literature on Facebook in fact suggests that the social network serves more the preservation of relations among offline contacts than the activation of latent ties or the creation of connections with strangers (Ellison et al., 2007). Most Facebook friend connections indeed represent in-person relationships (Ellison et al., 2011). For example, Pénard and Poussing (2010) draw on data from the 2002 wave of the European Social Survey for Luxembourg to find that people who already have a large stock of social capital are more likely to use the Internet to take care of their social relationships.

Antoci and Bartolini $(1999,2004)$ theoretically analyse how the expansion of private production may erode the quality of commonly owned goods, thereby forcing individuals to increasingly rely on private goods to satisfy their needs. As a result of this 'negative externality of growth', individuals increase their labour supply in order to produce substitutes for the diminishing resource. In the context addressed in the present paper, this process may be related to a decrease in the production of relational goods that could in turn cause the erosion of the stock of social capital. This latter hypothesis is explicitly modelled in Antoci et al. (2001, 2005, 2007, 2008) and Bartolini and Bonatti (2008) who argue that the progressive 'marketization' of social life, namely the process through which market relations become more pervasive, may contribute to the diffusion of values, attitudes and behaviours that do not favour social relations and the formation of social capital. The authors

(C) 2013 Blackwell Publishing Ltd 
show that, in the long run, an economy that grows faster tends to be relatively poorer in the quality of social environment.

Drawing on a pooled cross-section of nine waves of the General Social Survey, Bartolini and Bilancini (2011) use a structural equations model to empirically test the hypothesis that an increase in the labour supply may crowd out social participation. The authors find that, in the USA, there is a significant and negative correlation between the number of hours worked and social participation as measured by membership in Putnam-esque associations - i.e. those associations which do not act as 'distributional coalitions but which involve social interactions that can build trust and cooperative habits' (Knack and Keefer, 1997, p. 1273). Labour supply seems not to affect membership in Olsonian associations (organizations which have redistributive goals and thus lobby for the protection of their members' interests). Unfortunately, available data do not allow to test the relationship between the number of hours worked and other kinds of relational goods such as those whose production and consumption are explicitly addressed in this paper.

Finally, we assume that the instantaneous utility function of individual $i$ is:

$$
U_{i}\left[C_{i}(t), P_{i}(t)\right]=\ln C_{i}(t)+b \ln P_{i}(t)
$$

where $P_{i}(t)$ and $C_{i}(t)$ represent the consumption, respectively, aimed to satisfy social and private needs, and $b>0$ measures the relative importance of social needs in respect to private ones. We assume that private goods can satisfy both private and social needs. If the surrounding environment is socially poor, agents may choose to replace human interactions with private consumption (e.g. they may stay at home watching television instead of meeting friends on a sports field). In contrast, relational goods cannot satisfy primary needs such as food, security, clothing and shelter. A simple way to describe this issue is to consider the following linear specification of $P_{i}(t)$ :

$$
P_{i}(t)=B_{i}(t)+d C_{i}(t)
$$

Note that, if $d>0$, then the mixed partial derivative of $U_{i}$ with respect to $C_{i}(t)$ and $B_{i}(t)$ is strictly negative:

$$
\frac{\partial^{2} U_{i}}{\partial C_{i} \partial B_{i}}=-\frac{b d}{\left(d C_{i}+B_{i}\right)^{2}}<0
$$

This means that $B_{i}(t)$ and $C_{i}(t)$ are Edgeworth substitutes, i.e. the lower the value of $B_{i}(t)$ is, the greater the marginal utility of private consumption $C_{i}(t)$ will be. The parameter $d$ describes the degree of (Edgeworth) substitutability 
between $B_{i}(t)$ and $C_{i}(t)$. In the limit case $d=0$, the two goods are not substitutes and the marginal utility of private consumption is not influenced by the consumption level of relational goods.

Letting $r$ be the discounting rate of future utility, the $i$-agent's maximization problem is:

$$
\max _{s_{i}(t)} \int_{0}^{+\infty}\left[\ln C_{i}(t)+b \ln P_{i}(t)\right] e^{-r t} d t
$$

subject to the dynamic constraint (3). The agent $i$ solves problem (7) taking as exogenously given the value of $K_{s}(t)$ and the average values $\bar{s}(t), \bar{B}(t)$ and $\bar{Y}(t)$ because the choice of $s_{i}(t)$ by agent $i$ does not modify the average values, being economic agents a continuum. Since individuals take $K_{s}(t)$ as exogenously given, their time allocation choices are aimed at maximizing, in each instant $t$ of time, the utility function (5). This implies that the dynamics of $K_{s}(t)$ we study do not represent the social optimum. However, since agent $i$ plays the best response $s_{i}(t)$, given the others' choices, the trajectories followed by $K_{s}(t)$ represent Nash equilibria. Along these trajectories, no agent has incentive to modify his choices if the other agents do not revise theirs as well.

To simplify our analysis, in this paper we focus on symmetric Nash equilibria. In particular, we assume that individuals are identical and make the same choices. This assumption allows us to study the choices of a representative agent. Thus we can omit the subscript $i$ in the variables $s_{i}(t), B_{i}(t), Y_{i}(t)$ and $C_{i}(t)$ writing simply $s(t), B(t), Y(t)$ and $C(t)$. In this symmetric Nash equilibrium context, we have that the values $\bar{s}(t), \bar{B}(t)$ and $\bar{Y}(t)$ are considered as exogenously given by the representative agent. However, once $s(t)$ is chosen, ex post it holds:

$$
\begin{aligned}
& \bar{s}(t)=s(t) \\
& \bar{B}(t)=\bar{s}^{\varepsilon}(t) \cdot \bar{s}^{1-\varepsilon}(t) \cdot K_{s}^{\gamma}(t)=\bar{s}(t) \cdot K_{s}^{\gamma}(t)=s(t) \cdot K_{s}^{\gamma}(t) \\
& \bar{Y}(t)=[1-\bar{s}(t)] \cdot K_{s}^{\alpha}(t)=[1-s(t)] \cdot K_{s}^{\alpha}(t)
\end{aligned}
$$

In this context, the representative agent, in each instant of time $t$, chooses $s(t)$ solving the following static optimization problem:

$$
\max _{s}\left\{\ln \left[(1-s) K_{s}^{\alpha}\right]+b \ln \left[s^{\varepsilon^{1-\varepsilon}} K_{s}^{\gamma}+d(1-s) K_{s}^{\alpha}\right]\right\}
$$

taking as exogenously given the values of $\bar{s}$ and $K_{s}$. The solution $s(t)$ of the problem (8) has to be substituted to $\bar{s}(t)$ in equation (3) which, under our symmetric Nash equilibria assumption, can be written as follows: 


$$
\begin{aligned}
\dot{K}_{s}(t) & =[\bar{Y}(t)]^{\beta}[\bar{B}(t)]^{\delta}-\eta K_{s}(t)= \\
& =\left[[1-\bar{s}(t)] K_{s}^{\alpha}(t)\right]^{\beta}\left[\bar{s}^{\varepsilon}(t) \bar{s}^{1-\varepsilon}(t) K_{s}^{\gamma}(t)\right]^{\delta}-\eta K_{s}(t)= \\
& =[1-\bar{s}(t)]^{\beta}[\bar{s}(t)]^{\delta} K_{s}^{\alpha \beta+\gamma \delta}(t)-\eta K_{s}(t)
\end{aligned}
$$

Note that under dynamics (9), social capital accumulation is negative if $\bar{s}(t)=0$ (no social participation) or if $\bar{s}(t)=1$ (the production/consumption of the private good is equal to zero). As noted above, $\bar{B}(t)$ and $\bar{Y}(t)$ are in fact both essential factors for the accumulation of social capital. Thus, even if people devote all their time to social participation, the stock of social capital is doomed to erosion if there is no private production.

According to (9), the value of $\bar{s}(t)$ which, given $K_{s}(t)$, maximizes the rate of growth of $K_{s}(t)$ is $\bar{s}(t)=s^{g}:=\delta /(\beta+\delta)$. The latest expression can be interpreted as the 'golden rule' for the accumulation of social capital. Note that $s^{g} \rightarrow 0$ if $\delta \rightarrow 0$, and $s^{g} \rightarrow 1$ if $\beta \rightarrow 0$.

\section{ANALYSIS OF THE MODEL}

\subsection{The time allocation choice}

The following result concerns the choice of $s(t)$ by the representative agent (due to space constraints, proofs of the propositions are omitted if straightforward). ${ }^{2}$

Lemma 1: Problem (8) admits solution and the time allocation choice $s^{*}(t)$ of the representative agent is:

$$
s^{*}(t)= \begin{cases}0, & \text { if } K_{s}(t) \leq\left[\frac{d(b+1)}{b \varepsilon}\right]^{\frac{1}{\gamma-\alpha}} \\ \frac{b \varepsilon K_{s}^{\gamma-\alpha}(t)-d(b+1)}{(1+b \varepsilon) K_{s}^{\gamma-\alpha}(t)-d(b+1)}, & \text { if } K_{s}(t)>\left[\frac{d(b+1)}{b \varepsilon}\right]^{\frac{1}{\gamma-\alpha}}\end{cases}
$$

\footnotetext{
${ }^{2}$ For the sake of space and simplicity, we do not develop the case in which $\gamma=\alpha$. Anyway, for this peculiar parameter specification (the productivity of the social capital is the production process of the private and relational goods is the same), the time allocation is not influenced by the level of $K_{s}$. Thus the analysis of the social capital accumulation becomes similar to the one performed for (14).
} 
if $\gamma-\alpha>0$, and

$$
s^{*}(t)= \begin{cases}\frac{b \varepsilon K_{s}^{\gamma-\alpha}(t)-d(b+1)}{(1+b \varepsilon) K_{s}^{\gamma-\alpha}(t)-d(b+1)}, & \text { if } K_{s}(t) \leq\left[\frac{d(b+1)}{b \varepsilon}\right]^{\frac{1}{\gamma-\alpha}} \\ 0, & \text { if } K_{s}(t)>\left[\frac{d(b+1)}{b \varepsilon}\right]^{\frac{1}{\gamma-\alpha}}\end{cases}
$$

if $\gamma-\alpha<0$.

Remember that $\gamma$ and $\alpha$ are the exponents of $K_{s}$ in the production functions of $B(t)$ and $Y(t)$, respectively. If $\gamma-\alpha>0$, then (ceteris paribus) an increase in the stock of social capital $K_{s}$ has the effect of raising the productivity of time spent on social participation $s(t)$ relative to that of time spent on the production and consumption of the private good, vice versa if $\gamma-\alpha<0$. In the former case, social participation $s(t)$ is increasing in $K_{s}$; if the stock of social capital is high enough, then social participation is positive $(s(t)>0)$, otherwise it is equal to zero and agents devote all their time to private production $(s(t)=0)$. In the latter case, social participation $s(t)$ is decreasing in $K_{s}$; in such a context, the opposite of case $\gamma-\alpha>0$ holds: if the stock of social capital is high enough, then agents specialize in the production/consumption of private goods while, if the stock of social capital is low, individuals devote a positive fraction of their time to social interaction. An implication of this result is that, according to (3), the stock of social capital cannot grow indefinitely when $\gamma-\alpha<0$. In this case, an increase in the stock of social capital raises the productivity of time spent on private production, thereby leading to a restriction of social participation, which in turn hampers the accumulation of social capital in the long run. In contrast, when $\gamma-\alpha>0$, an increase in the stock of social capital can trigger a self-feeding process resulting in an increase in the production/consumption of relational goods and in the stock of social capital.

If there is no substitutability between private consumption $C$ and the socially provided good $B$, i.e. $d=0$, then the following proposition holds.

Proposition 1: Under the assumption $d=0$, then the solution $s^{*}(t)$ of problem (8) is $s_{d=0}^{*}(t)=\frac{b \varepsilon}{1+b \varepsilon}$, whatever the value of $K_{s}(t)$ is.

When the two goods are not substitutes in the satisfaction of social needs, the reduction in the production/consumption of relational goods is not accompanied by an increase in the marginal utility of private goods. For 
example, the reduction of opportunities to go to the cinema with friends will not raise the marginal utility of devices to watch movies alone. In this case, private goods will not replace socially provided goods for the satisfaction of social needs, and social participation is always positive and constant. The analysis of both the cases $d=0$ and $d>0$ will allow a comparison between the 'limit' case in which $C$ is not a substitute for $B$ and the case in which there is some degree of substitutability between the two types of goods.

Notice that social participation $s^{*}(t)$ (see (10)-(11)) is a strictly decreasing function of the parameter $d$, so $s^{*}(t)<s_{d=0}^{*}(t)$ always holds. If agents admit the possibility of satisfying social needs (or compensating for their deprivation) through the production/consumption of private goods (e.g. a playstation being considered as a substitute for a match played on the tennis field), then the level of social participation is lower, whatever the value of $K_{s}(t)$ is.

\subsection{Dynamics of social capital accumulation and well-being analysis}

Even if we have considered very simple specifications of the functions $F$, $G$ and $H$, there may exist multiple steady states and poverty traps.

The following result concerns the evolution of representative agents' wellbeing along the trajectories under dynamics (9).

Proposition 2: Along the trajectories of (9), the values of the utility function $U$ and of $K_{s}$ are positively correlated. This implies that if there exist two steady states $K_{s}^{1}$ and $K_{s}^{2}$ such that $K_{s}^{2}>K_{s}^{1}$, then $K_{s}^{2}$ Pareto-dominates $K_{s}^{1}$, i.e. $K_{s}^{1}$ is a poverty trap.

The following proposition defines social capital dynamics resulting from the time allocation choices of the representative agent described in Lemma 1.

Proposition 3: If $\gamma-\alpha>0$, social capital dynamics are given by:

$$
\dot{K}_{s}= \begin{cases}-\eta K_{s}, & \text { if } K_{s} \leq\left[\frac{d(b+1)}{b \varepsilon}\right]^{\frac{1}{\gamma-\alpha}} \\ {\left[\frac{K_{s}^{\gamma-\alpha}}{(1+b \varepsilon) K_{s}^{\gamma-\alpha}-d(b+1)}\right]^{\beta} \cdot} & \text { if } K_{s}>\left[\frac{d(b+1)}{b \varepsilon}\right]^{\frac{1}{\gamma-\alpha}} \\ \cdot\left[\frac{b \varepsilon K_{s}^{\gamma-\alpha}-d(b+1)}{(1+b \varepsilon) K_{s}^{\gamma-\alpha}-d(b+1)}\right]^{\delta} K_{s}^{\alpha \beta+\gamma \delta}-\eta K_{s}, & \end{cases}
$$


If $\gamma-\alpha<0$, they are given by:

$$
\dot{K}_{s}= \begin{cases}{\left[\frac{K_{s}^{\gamma-\alpha}}{(1+b \varepsilon) K_{s}^{\gamma-\alpha}-d(b+1)}\right]^{\beta} \cdot} & \text { if } K_{s} \leq\left[\frac{d(b+1)}{b \varepsilon}\right]^{\frac{1}{\gamma-\alpha}} \\ \cdot\left[\frac{b \varepsilon K_{s}^{\gamma-\alpha}-d(b+1)}{(1+b \varepsilon) K_{s}^{\gamma-\alpha}-d(b+1)}\right]^{\delta} K_{s}^{\alpha \beta+\gamma \delta}-\eta K_{s}, & \text { if } K_{s}>\left[\frac{d(b+1)}{b \varepsilon}\right]^{\frac{1}{\gamma-\alpha}}\end{cases}
$$

In the following propositions we will address the cases with diminishing returns to scale of social capital $(\alpha \beta+\gamma \delta<1)$ and with constant returns to scale $(\alpha \beta+\gamma \delta=1)$ (see Sequeira and Ferreira-Lopes, 2011). In this latter case, an unbounded and perpetual growth of social capital is possible but it is not guaranteed (see Barro and Sala-i-Martin 2004). We will not consider the case with $\alpha \beta+\gamma \delta>1$ in that, in such a context, $K_{s}$ 'blows up' in finite time (i.e. $K_{s} \rightarrow+\infty$ for $t \rightarrow \bar{t}$, where $\bar{t}>0$ is a finite number, see Temple, 2003).

Notice that if $d=0$ (i.e. if relational and private goods are not substitutes), the dynamics of social capital accumulation become:

$$
\dot{K}_{s}=\frac{(b \varepsilon)^{\delta}}{(1+b \varepsilon)^{\beta+\delta}} \cdot K_{s}^{\alpha \beta+\gamma \delta}-\eta K_{s}
$$

and the corresponding dynamic regimes are described by the following proposition.

Proposition 4: Under the assumption of no Edgeworth substitutability $(d=0)$, the basic features of dynamics are the following (whatever the sign of the expression $\gamma-\alpha$ is):

(a) If $\alpha \beta+\gamma \delta<1$, then there exist two steady states:

$$
\bar{K}_{s}=\left[\frac{\eta(1+b \varepsilon)^{\beta+\delta}}{(b \varepsilon)^{\delta}}\right]^{\frac{1}{\alpha \delta+\gamma \delta-1}} \text { and } K_{s}=0
$$

and the economy approaches $\bar{K}_{s}$ (the steady-state $K_{s}=0$ is repulsive) whatever the initial value of $K_{s}>0$ is.

(b) If $\alpha \beta+\gamma \delta=1$, then:

(b.1) if $\frac{(b \varepsilon)^{\delta}}{(1+b \varepsilon)^{\beta+\delta}}<\eta$, then the economy approaches the unique steadystate $K_{s}=0$, whatever the initial value of $K_{s}$ is;

(b.2) if $\frac{(b \varepsilon)^{\delta}}{(1+b \varepsilon)^{\beta+\delta}}>\eta$, then the economy follows a trajectory along which the value of $K_{s}$ grows indefinitely (i.e. $K_{s} \rightarrow+\infty$ ) at the constant rate 
$\frac{(b \varepsilon)^{\delta}}{(1+b \varepsilon)^{\beta+\delta}}-\eta$, whatever the initial value of $K_{s}>0$ is (the unique steady-state $K_{s}=0$ is repulsive). ${ }^{3}$

If private goods cannot substitute relational ones in the satisfaction of social needs, then the economy can follow a virtuous trajectory where the stock of social capital unboundedly grows. However, when we assume $d$ to be strictly positive, then dynamics become more complicated and are characterized by the following propositions.

Proposition 5: If $\gamma-\alpha>0$, under the assumption of substitutability $(d>0)$, the dynamics are characterized by the following properties:

(1) The steady-state $K_{s}=0$ is always locally attractive (whatever the value of the expression $\alpha \beta+\gamma \delta$ is).

(2) If $\alpha \beta+\gamma \delta<1$ then the number of steady states with $K_{s}>0$ is (generically) zero (see figure 1) or two (see figure 2); if two steady states $K_{s}^{1}$ and $K_{s}^{2}$ $\left(K_{s}^{1}<K_{s}^{2}\right)$ exist, then $K_{s}^{2}$ is attractive while $K_{s}^{1}$ is repulsive.

(3) If $\alpha \beta+\gamma \delta=1$ then there exists at least one steady state with $K_{s}>0$; furthermore, the number of steady states with $K_{s}>0$ is one (see figure 3)

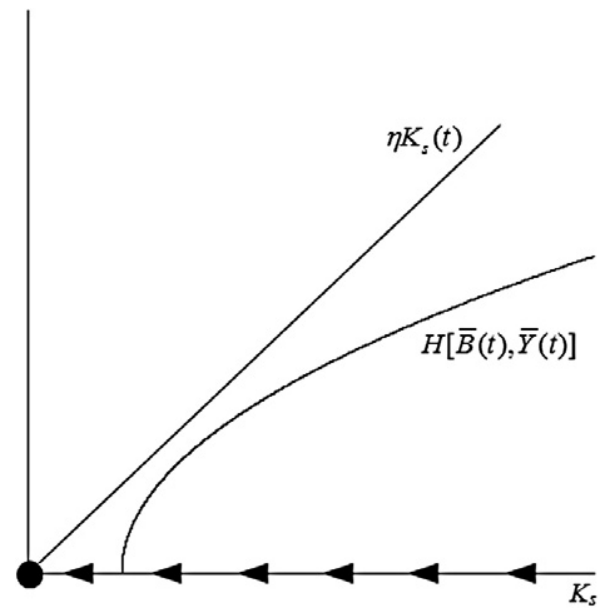

Figure 1. Context with $\gamma-\alpha>0$ and $\alpha \beta+\gamma \delta<1$ (Proposition 5). Case in which there exists a unique globally attractive steady-state $K_{s}=0$.

${ }^{3}$ If $\frac{(b \varepsilon)^{\delta}}{(1+b \varepsilon)^{\beta+\delta}}=\eta$, then $\dot{K}_{s}=0$ holds for every $K_{s}$. 


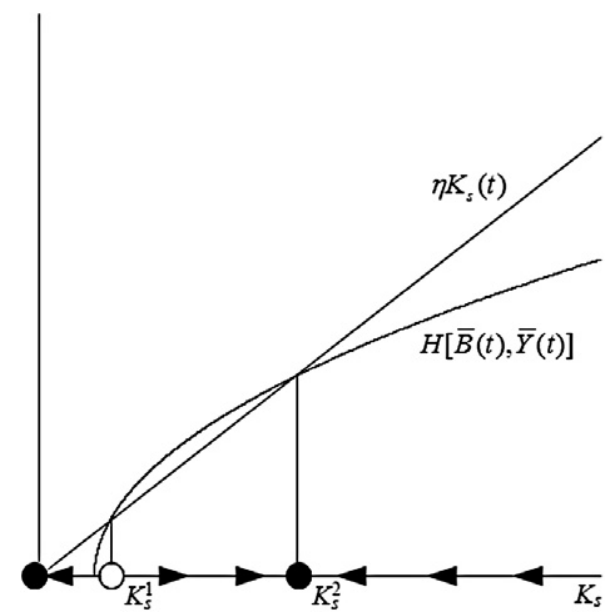

Figure 2. Context with $\gamma-\alpha>0$ and $\alpha \beta+\gamma \delta<1$ (Proposition 5). Case in which there exist two locally attractive steady states, $K_{s}=0$ and $K_{s}^{2}$, and their basins of attraction are separated by the repulsive steady-state $K_{s}^{1}<K_{s}^{2}$. The state $K_{s}=0$ is Pareto-dominated by $K_{s}^{2}$.

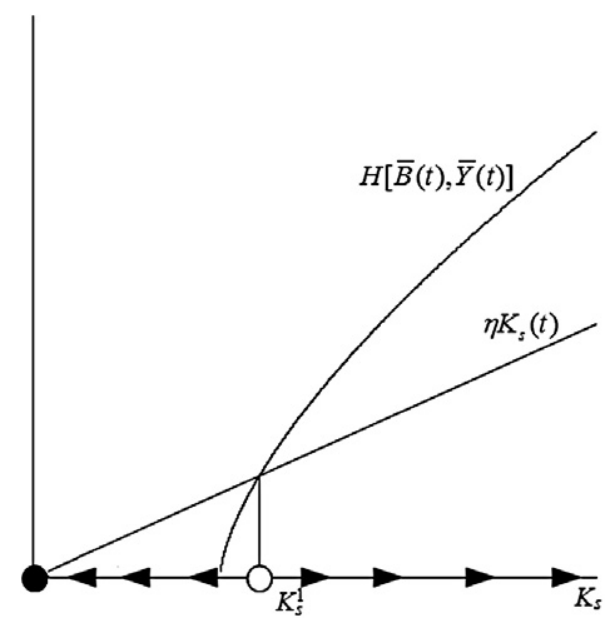

Figure 3. Context with $\gamma-\alpha>0$ and $\alpha \beta+\gamma \delta=1$ (Proposition 5). Case in which there exist two steady states, $K_{s}=0$ (attractive) and $K_{s}^{1}$ (repulsive); starting from $K_{s}(0)>K_{s}^{1}$, the economy follows a trajectory along which the stock $K_{\text {s }}$ grows without bound.

or three; if a unique steady state exists, then it is repulsive; if three steady states $K_{s}^{1}, K_{s}^{2}$ and $K_{s}^{3}\left(K_{s}^{1}<K_{s}^{2}<K_{s}^{3}\right)$ exist, then $K_{s}^{2}$ is attractive while $K_{s}^{1}$ and $K_{s}^{3}$ are repulsive. Finally, if $\frac{(b \varepsilon)^{\delta}}{(1+b \varepsilon)^{\beta+\delta}}>\eta$ and the initial value 
of $K_{s}$ is greater than $K_{s}^{*}$, where $K_{s}^{*}>0$ is the steady state with the highest value of $K_{s}$, then there exists an unbounded endogenous growth path with increasing well-being along which $K_{s} \rightarrow+\infty$ and $s \rightarrow \frac{b \varepsilon}{1+b \varepsilon}$.

If agents tend to replace relational goods with private ones for the satisfaction of social needs (or to compensate for the deprivation of human interactions), and if an increase in the stock of social capital $K_{s}$ has the effect of raising the productivity of time spent on social participation $s(t)$ relative to that of time spent on the production and consumption of the private good, then a steady state where $K_{s}=0$ is always locally attractive: an erosion of the entire stock of social capital is possible. However, it is also possible the existence of a growth trajectory along which $K_{s} \rightarrow+\infty$.

Under the assumption of substitutability $(d>0)$ and if $\gamma-\alpha<0$, the dynamics are described by the following proposition:

Proposition 6: If $\gamma-\alpha<0$, under the assumption of substitutability $(d>0)$, the dynamics are characterized by the following properties:

(1) The value of $K_{s}$ always approaches a steady-state value lower than the upper bound $\left[\frac{d(b+1)}{b \varepsilon+1}\right]^{\frac{1}{\gamma-\alpha}}$ (see Proposition 3), whatever the value of the expression $\alpha \beta+\gamma \delta$ is. Consequently, the stock of social capital $K_{s}$ cannot grow indefinitely.

(2) If $\alpha \beta+\gamma \delta<1$, then the steady-state $K_{s}=0$ is always repulsive; furthermore, there exists at least a steady state with $K_{s}>0$; the number of steady states with $K_{s}>0$ is (generically) one (see figure 4) or three; steady states with an odd index are attractive and those with an even index are repulsive. Whatever the initial value of $K_{s}$ is, the economy approaches a steady state with $K_{s}>0$.

(3) If $\alpha \beta+\gamma \delta=1$, then the steady-state $K_{s}=0$ is always locally attractive; the number of steady states with $K_{s}>0$ is zero (see figure 5) or two (see figure 6); the steady states with an odd index are repulsive and those with an even index are attractive.

High initial endowments of $K_{s}$ do not imply the possibility of an unbounded growth of the stock of social capital. From straightforward calculation it follows that necessary and sufficient conditions for the existence of a perpetual growth trajectory are the following:

$$
\frac{(b \varepsilon)^{\delta}}{(1+b \varepsilon)^{\beta+\delta}}>\eta, \quad \alpha \beta+\gamma \delta=1, \quad \gamma-\alpha>0
$$




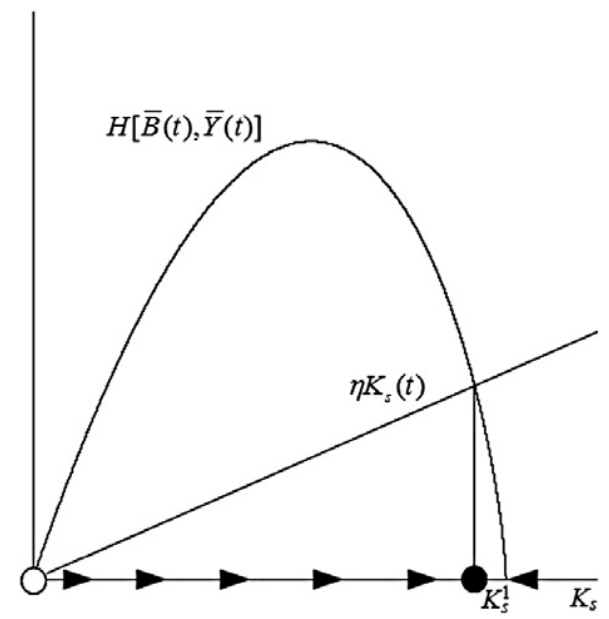

Figure 4. Context with $\gamma-\alpha<0$ and $\alpha \beta+\gamma \delta<1$ (Proposition 6). Case in which there exist a repulsive steady state, $K_{s}=0$, and a globally attractive steady state, $K_{s}^{1}$.

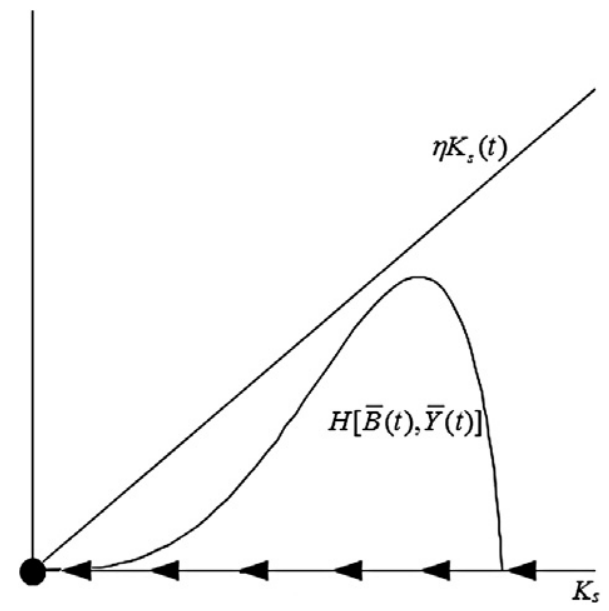

Figure 5. Context with $\gamma-\alpha<0$ and $\alpha \beta+\gamma \delta=1$ (Proposition 6). Case in which there exists a unique globally attractive steady-state $K_{s}=0$.

In case of Edgeworth substitutability, unbounded growth is not guaranteed even if there are constant returns to scale on $K_{s}$. The first two conditions are the same already seen in Proposition 4. However, the assumption of a positive degree of substitutability between the private good and the relational one entails that the allocation of the time spent on social participation is not 


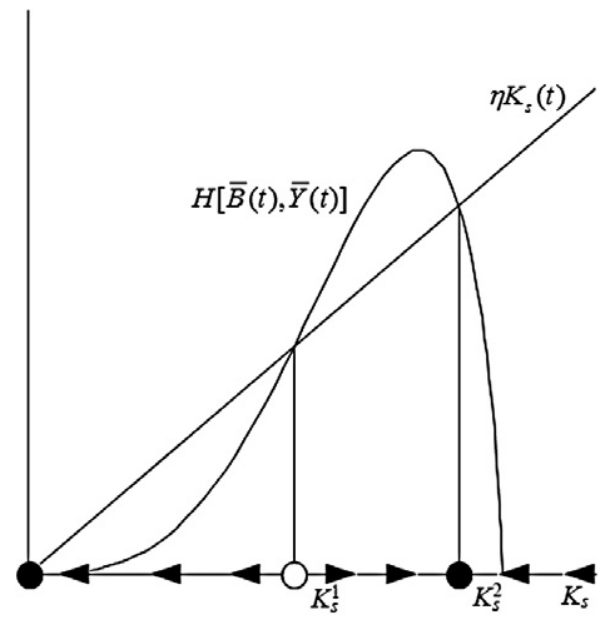

Figure 6. Context with $\gamma-\alpha<0$ and $\alpha \beta+\gamma \delta=1$ (Proposition 6). Case in which there exist two locally attractive steady states, $K_{s}=0$ and $K_{s}^{2}$, and their basins of attraction are separated by the repulsive steady-state $K_{s}^{1}<K_{s}^{2}$. The state $K_{s}=0$ is Pareto-dominated by $K_{s}^{2}$.

constant over time. Thus, the possibility to assist to an unbounded growth of $K_{s}$ requires the further condition $\gamma>\alpha$ (i.e. the contribution of the stock of social capital to the production of relational goods is higher than its contribution to the production of private goods) which causes a positive correlation between social capital $K_{s}$ and social participation $s(t)$.

When these conditions hold, the steady-state $K_{s}=0$ is always locally attractive. However, when the initial value of $K_{s}$ is high enough, the economy follows a trajectory along which $K_{s} \rightarrow+\infty$. As stated above, along this trajectory we have that $s(t)$ tends to $b \varepsilon /(1+b \varepsilon)$, thus the equation (12) 'tends' (for $K_{s} \rightarrow+\infty$ ) to the equation:

$$
\dot{K}_{s}=\frac{(b \varepsilon)^{\delta}}{(1+b \varepsilon)^{\beta+\delta}} K_{s}-\eta K_{s}
$$

which coincides with the equation (14) describing social capital dynamics under the assumption $d=0$ (no substitutability between $C$ and $B$ ). This allows us to say that when the stock of social capital becomes 'high enough', then the dynamics under the assumption $d=0$ and those under the assumption $d>0$ become very similar. This result is more likely if $b$ and $\varepsilon \in(0,1)$ exhibit high values and if the depreciation rate of social capital $\eta$ is low. As pointed out above, $b$ measures the weight of social needs in determining agents' satisfaction. A high value of $b$ indicates that agents are not so prone to sacrifice their relational sphere for private needs. Such parameters may be 
determined by cultural factors which acknowledge the importance of nonmarket relations in respect to material consumption. For example, a culture exalting the prominence of cooperation and solidarity in social life is a good starting point. The parameter $\varepsilon$ measures the productivity of the time spent in social participation by the representative agent. A high value of this parameter indicates that the representative agent is more capable of influencing his relational sphere with his own effort, independent of the current levels of social participation of others (the relevance of which is represented by the value of $1-\varepsilon$ ).

Figures 1-6 show Solow-like graphs, where the intersection points between $H[\bar{B}(t), \bar{Y}(t)]$ and $\eta K_{s}(t)$ are steady states of the dynamics (12)-(13). The full $\operatorname{dot}$ is used to represent attractive steady states while the empty dot $\bigcirc$ for repulsive ones.

\section{THE EFFECTS OF EXOGENOUS TECHNICAL PROGRESS}

In the introduction, we briefly reported how, according to Putnam (2000), the main channel leading to a reduction in social connectedness may be related to technology. In this section, we study the dynamic effects generated by the introduction of exogenous technical progress $T(t)$ in the production function of the private good:

$$
Y(t)=T(t) \cdot[1-s(t)] \cdot K_{s}^{\alpha}(t)
$$

where the growth process of $T$ is assumed to be given by the equation:

$$
\dot{T}(t)=\sigma T(t)
$$

where $\sigma$ is a strictly positive parameter representing the growth rate of $T$. In this context, the time allocation choice $s^{*}(t)$ by the representative agent is described by the following proposition.

Lemma 2: If the production function of the private good is given by (15), then problem (8) admits solution and the time allocation choice $s^{*}(t)$ of the representative agent is:

$$
s^{*}(t)= \begin{cases}0, & \text { if } K_{s}(t) \leq\left[\frac{d(b+1) T(t)}{b \varepsilon}\right]^{\frac{1}{\gamma-\alpha}} \\ \frac{b \varepsilon K_{s}^{\gamma-\alpha}(t)-d(b+1) T(t)}{(1+b \varepsilon) K_{s}^{\gamma-\alpha}(t)-d(b+1) T(t)}, & \text { if } K_{s}(t)>\left[\frac{d(b+1) T(t)}{b \varepsilon}\right]^{\frac{1}{\gamma-\alpha}}\end{cases}
$$


if $\gamma-\alpha>0$ and:

$$
s^{*}(t)= \begin{cases}\frac{b \varepsilon K_{s}^{\gamma-\alpha}(t)-d(b+1) T(t)}{(1+b \varepsilon) K_{s}^{\gamma-\alpha}(t)-d(b+1) T(t)}, & \text { if } K_{s}(t) \leq\left[\frac{d(b+1) T(t)}{b \varepsilon}\right]^{\frac{1}{\gamma-\alpha}} \\ 0, & \text { if } K_{s}(t)>\left[\frac{d(b+1) T(t)}{b \varepsilon}\right]^{\frac{1}{\gamma-\alpha}}\end{cases}
$$

if $\gamma-\alpha<0$.

\subsection{The case without substitutability between $\mathrm{C}$ and $\mathrm{B}$}

If there is no substitutability between the private consumption $C$ and the relational good $B$ (i.e. if $d=0$ ), social participation is constant and strictly positive: $s^{*}(t)=b \varepsilon /(1+b \varepsilon)$. In this context, the dynamic of the accumulation of social capital is given by the equation:

$$
\dot{K}_{s}=\frac{(b \varepsilon)^{\delta}}{(1+b \varepsilon)^{\beta+\delta}} T^{\beta} K_{s}^{\alpha \beta+\gamma \delta}-\eta K_{s}
$$

where the evolution of $T$ is described by the differential equation (16). Note that $\dot{K}_{s}=0$ for $K_{s}=0$ and, if $\alpha \beta+\gamma \delta<1$, along the graph of the function (denoted by $\Gamma$ in figure 7 ):

$$
K_{s}=\left[\frac{(b \varepsilon)^{\delta}}{\eta(1+b \varepsilon)^{\beta+\delta}}\right]^{\frac{1}{1-\alpha \beta-\gamma \delta}} T^{\frac{\beta}{1-\alpha \beta-\gamma \delta}}
$$

which is increasing in $T$. Note that it holds $\dot{K}_{s}<0$ above the curve (20) and $\dot{K}_{s}>0$ below it.

The basic features of dynamics under the assumption of no substitutability are described by the following proposition.

Proposition 7: Dynamics (19) have the following properties:

(1) If $\alpha \beta+\gamma \delta<1$, then both $T$ and $K_{s}$ grow without bound (i.e. $\lim _{t \rightarrow+\infty} T(t)=+\infty$ and $\left.\lim _{t \rightarrow+\infty} K_{s}(t)=+\infty\right)$ along any trajectory starting from a strictly positive initial value of $K_{s}$. Among these trajectories, there exists a trajectory represented by the equation:

$$
K_{s}=\left\{\frac{(1-\alpha \beta-\gamma \delta)(b \varepsilon)^{\delta}}{[\beta \sigma+\eta(1-\alpha \beta-\gamma \delta)](1+b \varepsilon)^{\beta+\delta}}\right\}^{\frac{1}{1-\alpha \beta-\gamma \delta}} T^{\frac{\beta}{1-\alpha \beta-\gamma \delta}}
$$


along which the growth rates of $T$ and $K_{s}$ are given by:

$$
\frac{\dot{K}_{s}}{K_{s}}=\frac{\beta}{(1-\alpha \beta-\gamma \delta)} \frac{\dot{T}}{T}
$$

where $\frac{\dot{T}}{T}=\sigma$ by assumption and $\frac{\dot{K}_{s}}{K_{s}}>\frac{\dot{T}}{T}$ if and only if $\frac{\beta}{1-\alpha \beta-\gamma \delta}>1$. Along the remaining trajectories, the growth rate of $K_{s}$ approaches the value given in (22) as $t \rightarrow+\infty$ (see figure 7).

(2) If $\alpha \beta+\gamma \delta=1$, then an explicit solution of (19) can be calculated:

$$
K_{s}(t)=K_{s}(0) \exp \left(A \cdot T(0)^{\beta}(\exp (\beta \sigma t)-1)-\eta \beta \sigma t\right)
$$

where $A=\frac{(b \varepsilon)^{\delta}}{(1+b \varepsilon)^{\beta+\delta}}$ while $K_{s}(0)$ and $T(0)$ are the initial conditions on social capital and technology.

Proof: The first part of Proposition 7 can be proved by defining a new variable:

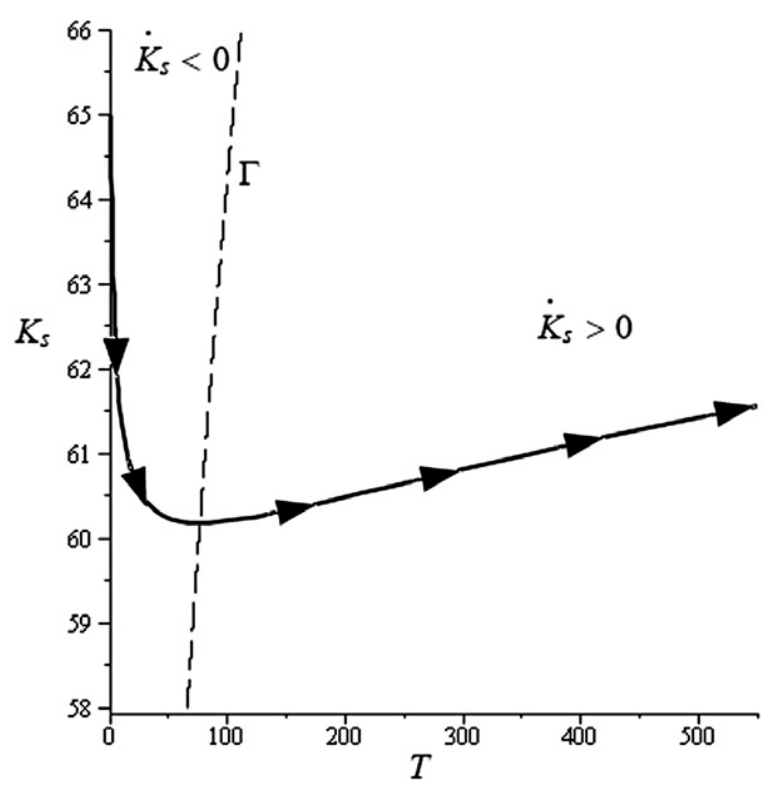

Figure 7. The context without substitutability between $\mathrm{B}$ and $\mathrm{C}$. When $\mathrm{T}$ increases, the evolution of $K_{s}$ may be monotonic (always increasing) or may follow a $U$-shaped path, according to which $K_{s}$ initially decreases and then becomes definitively increasing, as the trajectory in this figure shows. 


$$
x:=\frac{T^{\beta}}{K_{s}^{1-(\alpha \beta+\gamma \delta)}}
$$

and by calculating its time derivative:

$$
\begin{aligned}
\dot{x} & =\frac{T^{\beta}}{K_{s}^{1-(\alpha \beta+\gamma \delta)}}\left\{\beta \frac{\dot{T}}{T}-[1-(\alpha \beta+\gamma \delta)] \frac{\dot{K}_{s}}{K_{s}}\right\}= \\
& =x\left\{[\beta \sigma+\eta(1-\alpha \beta-\gamma \delta)]-\frac{(b \varepsilon)^{\delta}}{(1+b \varepsilon)^{\beta+\delta}}(1-\alpha \beta-\gamma \delta) x\right\}
\end{aligned}
$$

Equation (24) has two stationary states:

$$
x^{*}=0 \quad \text { and } \quad x^{* *}=\frac{[\beta \sigma+\eta(1-\alpha \beta-\gamma \delta)](1+b \varepsilon)^{\beta+\delta}}{(1-\alpha \beta-\gamma \delta)(b \varepsilon)^{\delta}}
$$

Notice that, since $\alpha \beta+\gamma \delta<1$, then $\mathrm{x}^{* *}>0$ is globally attractive in the positive $x$-axis; since, by (24), $\dot{x}=0$ if and only if (22) holds, point (1) of proposition is proved. The second part is straightforward.

It is interesting to note that:

(1) If there is no substitutability between $C$ and $B$, then $K_{s}$ can grow indefinitely, whatever the sign of the expression $\gamma-\alpha$ is (we will show later that this result no longer holds when there is substitutability).

(2) Along the trajectories under dynamics (19), the evolution of $K_{s}$ is always increasing or follows a U-shaped path, according to which $K_{s}$ initially decreases and then becomes definitively increasing. It is worthwhile to stress this result in that, as we will see, if there is substitutability between $C$ and $B$, then the evolution of $K_{s}$ can take the shape of an inverted $\mathrm{U}$ curve.

\subsection{The case with substitutability between $\mathrm{C}$ and $\mathrm{B}$}

If $d>0$, then social participation $s^{*}$ depends on the values of $T$ and $K_{s}$ and can assume the value 0 . In particular, the graph of the function (denoted by $\Gamma_{1}$ in figure 8):

$$
K_{s}=\left[\frac{d(b+1) T}{b \varepsilon}\right]^{\frac{1}{\gamma-\alpha}}
$$


separates, in the plane $\left(T, K_{s}\right)$, the region where $s^{*}=0$ (below the curve) from that where $s^{*}>0$ (above it). Note that the function (25) is increasing (decreasing) in $T$ if $\gamma-\alpha>0$ (respectively, if $\gamma-\alpha<0$ ).

In the region where $s^{*}=0$, social capital dynamics are given by $\dot{K}_{s}=-\eta K_{s}<0$ and the slope $\frac{d K_{s}}{d T}=-\frac{\eta K_{s}}{\sigma T}$ of the trajectories is negative; this implies that along the trajectories below the curve (25), $T$ increases and $K_{s}$ decreases.

Above the curve (25), social capital dynamics are given by:

$$
\dot{K}_{s}=\left[\frac{K_{s}^{\gamma-\alpha}}{(1+b \varepsilon) K_{s}^{\gamma-\alpha}-d(b+1) T}\right]^{\beta} \cdot\left[\frac{b \varepsilon K_{s}^{\gamma-\alpha}-d(b+1) T}{(1+b \varepsilon) K_{s}^{\gamma-\alpha}-d(b+1) T}\right]^{\delta} \cdot T^{\beta} K_{s}^{\alpha \beta+\gamma \delta}-\eta K_{s}
$$

where $T$ evolves according to the differential equation (16).

The basic features of dynamics (26) are described in the following proposition.

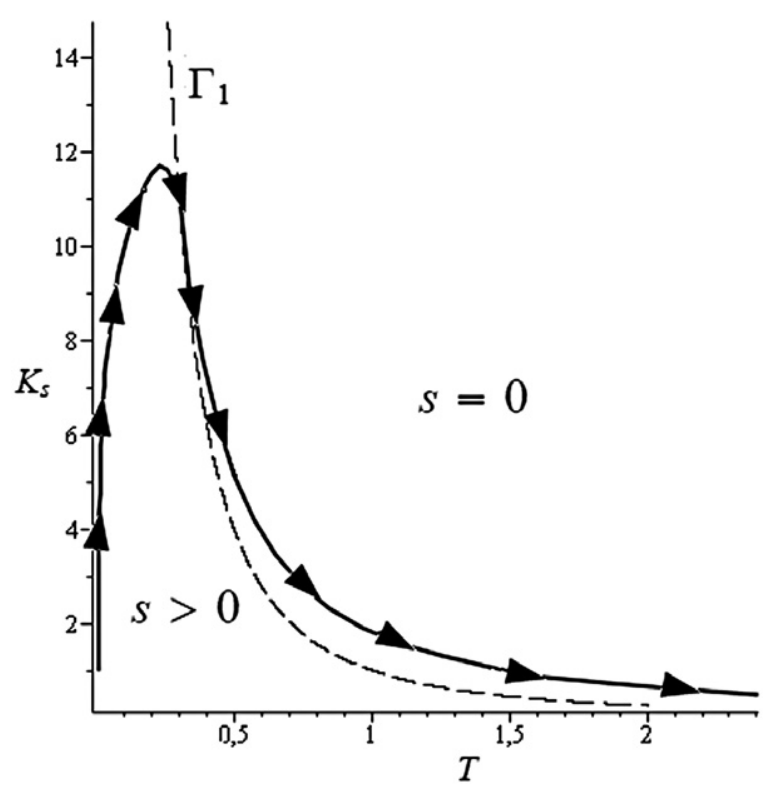

Figure 8. The context with substitutability between $\mathrm{B}$ and $\mathrm{C}$, case $\gamma-\alpha<0$. When $\mathrm{T}$ increases, the evolution of $K_{s}$ may be monotonic (always decreasing) or may follow an inverted $U$-shaped path, according to which $K_{s}$ initially increases and then becomes definitively decreasing, as the trajectory in this figure shows. 
Proposition 8:

(1) If $\gamma-\alpha<0$, then the region above (under) the curve (25) is positively invariant if $\sigma \geq \eta(\alpha-\gamma)$ (respectively, if $\sigma<\eta(\alpha-\gamma)$ ); in any case, along every trajectory the value of $K_{s}$ approaches 0 for $t \rightarrow+\infty$ (see figure 8);

(2) If $\gamma-\alpha>0$, then the region under the curve (25) is positively invariant under dynamics: every trajectory entering this region cannot leave it. Along the trajectories under the curve (25), the value of $K_{s}$ approaches 0 for $t \rightarrow+\infty$ (see figure 9).

Proof: To check the results about the positive invariance of the sets under or above the curve (25), we simply have to compare the slope of the trajectories $\frac{d K_{s}}{d T}=-\frac{\eta K_{s}}{\sigma T}$, evaluated along the curve (25), and the slope of (25). To prove the results about the evolution of $K_{s}$, notice that in the set where $s^{*}=0$ it holds $\dot{K}_{s}=-\eta K_{s}$ and consequently $K_{s}(t)=K_{s}(0) \cdot e^{-\eta t}$, where $K_{s}(0)$ is the initial value of $K_{s}$. Finally, note that in case $\gamma-\alpha<0$, every trajectory lies

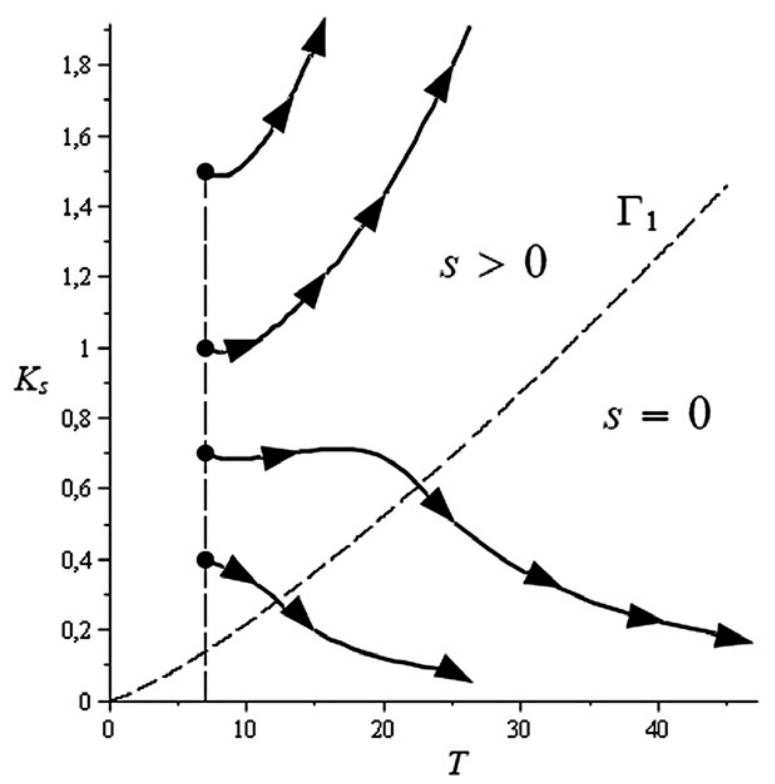

Figure 9. The context with substitutability between $\mathrm{B}$ and $\mathrm{C}$, case $\gamma-\alpha>0$. Path-dependence occurs: if the initial value of $K_{s}$ is high enough, then the stock $K_{s}$ grows without bound, otherwise it may follow an inverted $U$-shaped path. 
definitively in the set under the curve (25) or in the set above it; in any case, since $T \rightarrow+\infty$, the value of $K_{s}$ approaches 0 .

Whatever the sign of the expression $\gamma-\alpha$ is, along the trajectories crossing the curve (25) we will show that the evolution of $K_{s}$ can take an inverted $\mathrm{U}$ shape, different from the case without substitutability.

According to the above proposition, a necessary condition to have unbounded growth of $K_{s}$ is $\gamma-\alpha>0$, i.e. the importance of $K_{s}$ as an input in the production process of the private good (measured by $\alpha$ ) must be lower than its importance in the production process of the relational good (measured by $\gamma$ ).

To analyse the behaviour of $K_{s}$ in case $\gamma-\alpha>0$ we introduce the following definition.

Definition: A Regular Growth Curve ( $R G C$ ) is a curve in the plane $\left(T, K_{s}\right)$ along which the rate of growth of $T$ is equal to the exogenously given value $\sigma$ while the rate of growth of $K_{s}$ is equal to a constant strictly positive value $g$, possibly different from $\sigma$.

Notice that along a $R G C$, being $\frac{\dot{T}}{T}=\sigma$ and $\frac{\dot{K}_{s}}{K_{s}}=g$, it holds $\frac{d K_{s}}{d T}=\frac{\dot{K}_{s}}{T}=$ $\frac{g K_{s}}{\sigma T}$; consequently a $R G C$ is the graph of a function $K_{s}(T)=A T^{\frac{g}{\sigma}}$, where $A$ is a positive arbitrary constant. RGCs are not trajectories under our dynamics. However, we aim to show that, for a high enough value of $T$, there exist values of $g$ and $A$, which we will denote by $\bar{g}$ and $\bar{A}$, respectively, such that the corresponding $\operatorname{RGC} K_{s}(T)=\bar{A} T^{\frac{\bar{g}}{\sigma}}$ is asymptotically approached, for $T \rightarrow+\infty$, by all the trajectories starting 'near' it. This implies that, along such trajectories, $\frac{\dot{K}_{s}}{K_{s}} \rightarrow \bar{g}$ as $t \rightarrow+\infty$.

Notice that, for a high enough value of $T$, a $R G C$ can be approached by the trajectories only if it lies above the curve (25) (which is a separatrix); this requires that $g$ must satisfy the necessary condition: $\frac{g}{\sigma}>\frac{1}{\gamma-\alpha}$, where $\frac{1}{\gamma-\alpha}>1$. That is, it must hold $g>\frac{\sigma}{\gamma-\alpha}$ (where $\left.\frac{\sigma}{\gamma-\alpha}>\sigma\right)$, so we introduce a further definition.

Definition: A Reachable Regular Growth Curve (RRGC) is a RGC satisfying the condition $g>\frac{\sigma}{\gamma-\alpha}$. 
Looking at (17), it is easy to check that, along a $R R G C$, the social participation choice $s^{*}$ approaches the value $\frac{b \varepsilon}{1+b \varepsilon}$ as $t \rightarrow+\infty$. Remember that $\frac{b \varepsilon}{1+b \varepsilon}$ is the value of social participation in the context without substitutability. In other words, if $T$ and $K_{s}$ grow following a $R R G C$, then for high enough values of $T$ and $K_{s}$, social participation is almost equal to the level achieved under the assumption of no substitutability. Now the problem is: are there values of $g$ and $A$ such that the associated $R R G C$ can be approached by some trajectories of the dynamics? To solve this problem, we analyse the behaviour of the variable $x$ previously defined (see (23)) and limit our analysis to the case $1-\alpha \beta-\gamma \delta>0$. Remember that in the context in which $s^{*}=\frac{b \varepsilon}{1+b \varepsilon}$ always holds (i.e. in the context without substitutability), we have $\dot{x}=0$ (see (25)) along the curve (see (21)) $K_{s}=\bar{A} \cdot T^{\frac{\bar{g}}{\sigma}}$, where:

$$
\bar{A}:=\left\{\frac{(1-\alpha \beta-\gamma \delta)(b \varepsilon)^{\delta}}{[\beta \sigma+\eta(1-\alpha \beta-\gamma \delta)](1+b \varepsilon)^{\beta+\delta}}\right\}^{\frac{1}{1-\alpha \beta-\gamma \delta}}
$$

and $\bar{g}:=\frac{\beta}{1-\alpha \beta-\gamma \delta}$. So, if $\frac{\beta \sigma}{1-\alpha \beta-\gamma \delta}>\frac{\sigma}{\gamma-\alpha}$, i.e. $\frac{\beta(\gamma-\alpha)}{1-\alpha \beta-\gamma \delta}>1$, we have that, as $T \rightarrow+\infty$, along $K_{s}=\bar{A} \cdot T^{\frac{\bar{g}}{\sigma}}$ the value of $\dot{x}$ approaches 0 while $\dot{x}$ becomes (see (24)) strictly positive (respectively, strictly negative) along the $R R G C s$ corresponding to values of $g<\bar{g}$ (respectively, $g>\bar{g}$ ), with $g$ and $A$ near enough to $\bar{g}$ and $\bar{A}$, respectively. This implies that all trajectories starting (for a high enough value of $T$ ) sufficiently near to $K_{s}=\bar{A} \cdot T^{\frac{\bar{g}}{\sigma}}$ approach $K_{s}=\bar{A} \cdot T^{\frac{\bar{g}}{\sigma}}$ as $T \rightarrow+\infty$. Notice that, by Proposition 2, all trajectories in the plane $\left(T, K_{s}\right)$ can be Pareto-ranked; in particular, we have that given two trajectories $\tilde{K}_{s}(T)$ and $\hat{K}_{s}(T)$, with $\tilde{K}_{s}(T)<\hat{K}_{s}(T)$, then $\hat{K}_{s}(T)$ Paretodominates $\tilde{K}_{s}(T)$. Furthermore, well-being may be decreasing when the economy follows a trajectory along which $K_{s} \rightarrow 0$ (see figures 10 and 11).

\section{CONCLUDING REMARKS}

In our economy, individuals have to allocate their time between labour aimed at the production of private goods and social participation activities. Private consumption and relational goods are substitutable: if the environment is poor in participation opportunities and social participation is perceived as costly and frustrating, people can disengage from relational activities and 


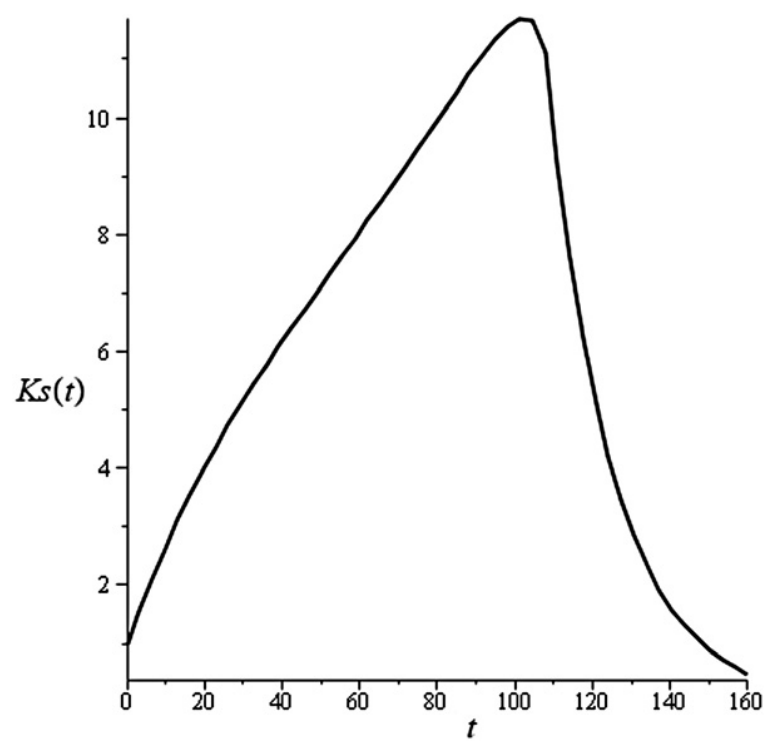

Figure 10. The context with substitutability between $\mathrm{B}$ and $\mathrm{C}$. The time evolution of $K_{s}$ along a trajectory following an inverted U-shaped path.

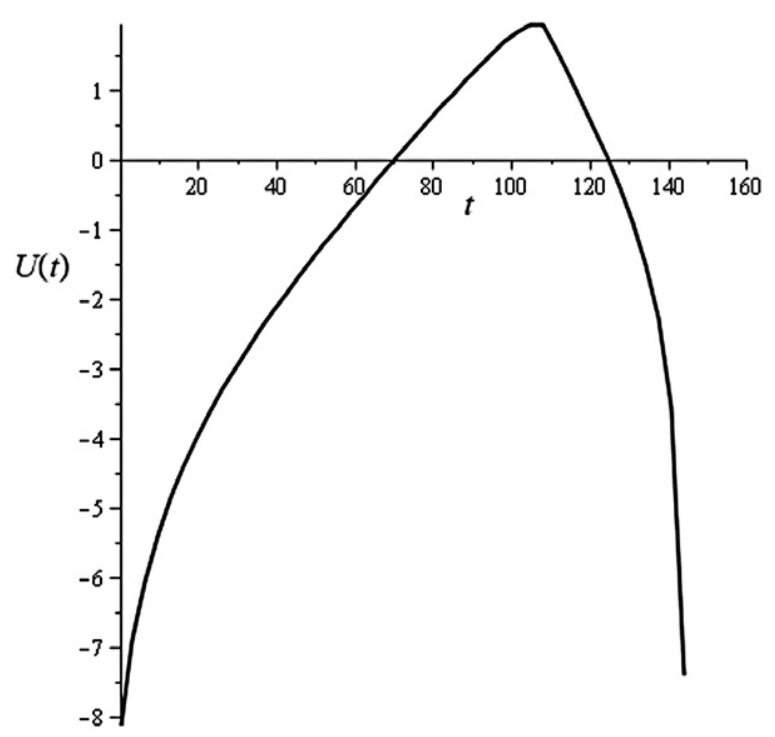

Figure 11. The context with substitutability between $\mathrm{B}$ and $\mathrm{C}$. The time evolution of well-being along the trajectory illustrated in figure 10.

(C) 2013 Blackwell Publishing Ltd 
devote more time and resources to private consumption. Following insights from Hochschild (1997) and Putnam (2000), we account for the possibility of positive spillovers of private production on the accumulation process of social capital, due to the ability of on-the-job interactions to stimulate the creation of durable ties. Following Coleman (1988, 1990), we assume that most of the time the creation of interpersonal ties does not depend on rational investment decisions. Rather, it is an incidental by-product of social participation. The resulting stock is a public resource, which enters as an argument in individuals' utility functions and as an input in the production functions of private and relational goods. The main results of our study can be summarized as follows.

In the framework without technological progress, an unbounded growth of social capital can be observed only in the following two cases:

(a) The case in which private goods and relational goods are not Edgeworth substitutes.

(b) The case in which the two types of goods are Edgeworth substitutes but the relevance of the impact exerted by the stock of social capital on the production/consumption process of relational goods is greater than that exerted on the production process of private ones (i.e. $\gamma-\alpha>0$ ).

In both cases (a) and (b), social capital dynamics are path-dependent. In a 'favourable' configuration of the model's parameters, starting from a high enough initial endowment of social capital, the economy follows a virtuous trajectory where the stock of social capital endogenously and unboundedly grows, raising social participation and consolidating interpersonal ties. On the other hand, the reverse process may also be self-feeding: if the initial endowment of social capital is low, then the economy experiences a simultaneous decline in social participation and social capital, leading to a 'social poverty trap' where the time spent on relational activities becomes more expensive (in terms of opportunity cost) and less productive (in terms of relational goods).

If private and relational goods are substitutes but (b) does not hold (i.e. $\gamma-\alpha<0$ ), then no trajectory exists along which social capital grows without bound.

In the context without technological progress, the evolution of social capital is always monotonic, always increasing or decreasing. The introduction of exogenous technical progress in the production function of private goods leads to interesting modifications in the accumulation dynamics of social capital. In this context, the trend of social capital relative to technological progress can be non-monotonic. In particular, it may experience an 
initial decline followed by growth, but not vice versa, if relational and private goods are not substitutes. Under the assumption of positive substitutability, the stock of social capital may exhibit a growth followed by a decline, so that its relationship with technological progress is described by an inverted U-shaped curve.

This result is consistent with the inverted U-shaped trends that several indicators of social participation followed in the 20th century (Putnam, 2000).

Also under the assumption of exogenous technical progress, there exist trajectories along which social capital can grow without bound only in the contexts (a) and (b) described above. The possibility of finding the path to a sustainable growth of social capital crucially depends on the initial endowment of its stock: an environment rich in participation opportunities, a culture that acknowledges the importance of non-market relations and the diffusion of moral norms of reciprocity and cooperation certainly constitute a good 'starting point'.

This paper represents a new step in a research programme aimed at theoretically analysing the accumulation of social capital in relation to economic growth and technological progress. In a previous work (Antoci et al., 2012b), we analysed the accumulation of social capital as a function of the aggregate social participation and current social capital levels. In this paper, we model the additional hypothesis that the accumulation of social capital may be affected by the process of production of private goods as well, as claimed by the literature reviewed in section 2 . The higher analytical simplicity related to the use of a logarithmic utility function - instead of the constant elasticity of substitution (CES) function adopted in Antoci et al. (2012a), allows us to carry out a more in-depth analysis of the dynamics of the interplay between social capital accumulation and technical progress which leads to interesting results. More specifically, we point out which conditions may lead the evolution of social capital to follow an inverted $\mathrm{U}$ path, thereby providing a theoretical explanation of the hypothesis advanced by Putnam (2000) based on US empirical evidence.

\section{REFERENCES}

Antoci, A., Bartolini, S. (1999): 'Negative externalities as the engine of growth in an evolutionary context', FEEM Working Paper No. 83-99.

Antoci, A., Bartolini, S. (2004): 'Negative externalities, defensive expenditures and labor supply in an evolutionary context', Environment and Development Economics, 9, pp. 591-612.

Antoci, A., Sacco, P. L., Vanin, P. (2001): 'Economic growth and social poverty: the evolution of social participation', Discussion paper 13/2001, Bonn Econ Discussion Papers, University of Bonn. 
Antoci, A., Sacco, P. L., Vanin, P. (2005): 'On the possible conflict between economic growth and social development', in Gui, B., Sugden, R. (eds): Economics and Social Interaction: Accounting for Interpersonal Relations, Cambridge University Press, Cambridge.

Antoci, A., Sacco, P. L., Vanin, P. (2007): 'Social capital accumulation and the evolution of social participation', Journal of Socio-Economics, 35, pp. 128-43.

Antoci, A., Sacco, P. L., Vanin, P. (2008): 'Participation, growth and social poverty: social capital in a homogeneous society', Open Economics Journal, 1, pp. 1-13.

Antoci, A., Sabatini, F., Sodini, M. (2012a): 'Bowling alone but tweeting together: the evolution of human interaction in the social networking era', Quality and Quantity (forthcoming).

Antoci, A., Sabatini, F., Sodini, M. (2012b): 'The solaria syndrome: social capital in a hypertechnological growing economy', Journal of Economic Behavior and Organization, 81 (3), pp. 802-14.

Antoci, F., Sabatini, F., Sodini, M. (2012c): 'See you on Facebook! A framework for analyzing the role of computer-mediated interaction in the evolution of social capital', Journal of Socio-Economics, 41, pp. 541-7.

Barro, R., Sala-i-Martin, X. (2004): Economic Growth, The MIT Press, Cambridge, MA.

Bartolini, S., Bilancini, E. (2011): 'Social Participation and Hours Worked', University of Siena Department of Economics Working paper No. 620.

Bartolini, S., Bonatti, L. (2008): 'Endogenous growth, decline in social capital and expansion of market activities', Journal of Economic Behavior and Organization, 67, pp. 917-26.

Bauernschuster, S., Falck, O., Woessmann, L. (2011): 'Surfing alone? The Internet and social capital: evidence from an unforeseeable technological mistake', SOEP WP 392.

Beugelsdijk, S., van Schaik, A. B. T. M. (2005): 'Social capital and growth in European regions: an empirical test', European Journal of Political Economy, 21, pp. 301-25.

Bilancini, E., D’Alessandro, S. (2012): 'Long-run welfare under externalities in consumption, leisure, and production: a case for happy degrowth vs. unhappy growth', Ecological Economics, 84, pp. 194-205. doi:dx.doi.org/10.1016/j.ecolecon.2011.10.023.

Bjørnskov, C. (2012): 'How does trust affect economic growth?', Southern Economic Journal, 78 (4), pp. 1346-68.

Brady, H. E., Verba, S., Schlozman, K. L. (1995): 'Beyond SES: a resource model of political participation', American Political Science Review, 89, pp. 271-94.

Burn, S. M., Konrad, A. M. (1987): 'Political participation: a matter of community, stress, job autonomy, and contact by political organizations', Political Psychology, 8, pp. 125-38.

Chaim, F., Gandal, N. (2011): 'Direct and indirect knowledge spillovers: the 'social network' of open source projects', RAND Journal of Economics, 42 (1), pp. 70-91.

Coleman, J. (1988): 'Social capital in the creation of human capital', American Journal of Sociology, 94, pp. 95-120.

Coleman, J. (1990): Foundations of Social Theory, Harvard University Press, Cambridge, MA.

Ellison, N. B., Steinfield, C., Lampe, C. (2007): 'The benefits of Facebook friends: social capital and college students' use of online social network sites', Journal of Computer-Mediated Communication, 12, pp. 1143-68.

Ellison, N. B., Steinfield, C., Lampe, C. (2011): 'Connection strategies: social capital implications of Facebook-enabled communication practices', New Media and Society, 13 (6), pp. 873-92.

Goul Andersen, J., Hoff, J. (2001): Democracy and Citizenship in Scandinavia, Palgrave, New York.

Gui, B., Sugden, R. (2005): 'Why interpersonal relations matter for economics', in Gui, B., Sugden, R. (eds): Economics and Social Interactions, Accounting for Interpersonal Relations, Cambridge University Press, Cambridge, MA.

Hochschild, A. R. (1997): The Time Bind. When Work Becomes Home and Home Becomes Work, Henry Holt and Company, New York. 
Knack, S., Keefer, P. (1997): 'Does social capital have an economic payoff?', The Quarterly Journal of Economics, 112 (4), pp. 1251-88.

Mutz, D. C., Mondak, J. J. (2006): 'The workplace as a context for cross-cutting political discourse', The Journal of Politics, 68, pp. 140-55.

Paldam, M., Svendsen, G. T. (2000): 'An essay on social capital: looking for the fire behind the smoke', European Journal of Political Economy, 18 (2), pp. 339-66.

Pasek, J., More, E., Romer, D. (2009): 'Realizing the social internet? Online social networking meets offline civic engagement', Journal of Information Technology and Politics, 6 (3-4), pp. $197-215$.

Pénard, T., Poussing, N. (2010): 'Internet use and social capital: the strength of virtual ties', Journal of Economic Issues, 44 (3), pp. 569-95.

Putnam, R. D. (2000): Bowling Alone: The Collapse and Revival of American Community, Touchstone Books, New York.

Routledge, B., von Amsberg, J. (2003): 'Social capital and growth', Journal of Monetary Economics, 50 (1), pp. 167-93.

Schur, L. (2003): 'Employment and the creation of an active citizenry', British Journal of Industrial Relations, 41, pp. 751-71.

Sequeira, T. N., Ferreira-Lopes, A. (2011): 'An endogenous growth model with human and social capital interactions', Review of Social Economy, 69 (4), pp. 465-93.

Temple, J. (2003): 'The long-run implications of growth theories', Journal of Economic Surveys, 17 (3), pp. 497-510.

Uhlaner, C. J. (1989): 'Relational goods and participation: incorporating sociability into a theory of rational action', Public Choice, 62, pp. 253-85.

Valenzuela, S., Park, N., Kee, K. F. (2009): 'Is there social capital in a social network site?: Facebook use and college students' life satisfaction, trust, and participation', Journal of Computer-Mediated Communication, 14, pp. 875-901.

Van Ingen, E., Dekker, P. (2011): 'Dissolution of associational life? Testing the individualization and informalization hypotheses on leisure activities in the Netherlands between 1975 and 2005', Social Indicators Research, 100, pp. 209-24.

Verba, S., Schlozman, K. L., Brady, H. E. (1995): Voice and Equality: Civic Voluntarism in American Politics, Harvard University Press, Cambridge, MA.

Vergeer, M., Pelzer, B. (2009): 'Consequences of media and Internet use for offline and online network capital and well-being. A causal model approach', Journal of Computer-Mediated Communication, 15 (1), pp. 189-210.

Wellman, B. (2001): 'Physical place and cyberplace: the rise of personalized networking', International Journal of Urban and Regional Research, 25 (2), pp. 227-52.

Angelo Antoci

Dipartimento di Scienze Economiche e Aziendali

Università di Sassari

Sassari

Italy

E-mail: antoci@uniss.it Italy

Mauro Sodini

Dipartimento di Economia

e Management

Università di Pisa

Pisa

Italy

E-mail:m.sodini@ec.unipi.it
Fabio Sabatini

Facoltà di Economia

Sapienza Università di Roma via del Castro Laurenziano 9 00161, Roma

E-mail: fabio.sabatini@uniroma1.it 